\title{
Atribuição de gravidade À DeficiênCia física em FunÇão da EXTENSÃO DO ACOMETIMENTO E DO CONTEXTO ESCOLAR
}

ATTRIBUTION OF SERIOUSNESS DEGREE TO PHYSICAL HANDICAP DUE TO INJURY

EXTENSION AND SCHOOL SETTING

\author{
Rita de Cássia Tibério ARAÚJO1 \\ Sadao OMOTE ${ }^{2}$
}

\begin{abstract}
RESUMO: a percepção que as pessoas têm da gravidade da deficiência é uma variável relevante a ser considerada na perspectiva da inclusão.Este estudo objetivou identificar a variação na atribuição de grau leve ou severo à deficiência física dependendo de quatro conjuntos de informações. Participaram do estudo 97 estudantes de um Curso de Pedagogia. O instrumento de coleta de dados, estruturado com base em texto descritivo acerca da necessidade de adaptação do teclado de computador para a realização da atividade de leitura e escrita por um aluno hipotético, contemplou duas possibilidades de extensão corporal de déficit motor e duas possibilidades de modalidade de ensino. A indicação da limitação de movimentos dos membros superiores caracterizou o acometimento parcial e a dos membros superiores e inferiores, além de dificuldade para manutenção do equilíbrio na posição sentada, representou o acometimento global. As modalidades de ensino foram informadas pela indicação do uso de recurso em classe comum e do uso de recurso em classe especial. Combinadas duas a duas, essas indicações compuseram quatro condições, cujos efeitos sobre a atribuição de gravidade ao acometimento motor foram analisados. As quatro condições receberam atribuição crescente de grau severo de acometimento motor e, conseqüentemente, atribuição decrescente de grau leve, na seguinte ordem: uso do recurso em classe comum e acometimento parcial, uso do recurso adaptado em classe comum e acometimento global, uso do recurso em classe especial e acometimento parcial e uso do recurso em classe especial e acometimento global. Os resultados demonstraram que a situação segregada de ensino e a informação sobre acometimento global tenderam a exacerbar a idéia de severidade da deficiência.
\end{abstract}

PALAVRAS-CHAVE: educação especial; deficiência física; gravidade da deficiência.

\begin{abstract}
: the perception people have about injury level of a disability is an important variable to be considered in the inclusion. This study aimed to identify the variation in the attribution of mild or severe injury to physical handicap depending upon four information sets. Ninety-seven Pedagogy students took part in the study. Data collecting instrument, consisting of a descriptive text concerning the need of computer keyboard adaptation for reading and written activity accomplishment by a hypothetical student, took account of two body conditions of motor deficit and two teaching settings. The indication of upper limb movement limitation characterized the partial injury. The global injury was represented by the indication of both upper limbs and lower ones movement limitation, besides difficulty in balance maintenance in seated position. The teaching settings were informed pointing out the use of adapted resource in regular class or in special class. Combining these indications, four conditions, whose effects on seriousness level attribution to the motor injury, were constituted. The four conditions received growing attribution of severe motor injury in following order: using adapted resource in regular class and partial injury, using adapted resource in regular class and global injury, using adapted resource in special class and partial injury and using adapted resource in special class and global injury. The results showed that the segregated teaching setting and global injury information tended toward maximization of the idea of injury severity.
\end{abstract}

KEYWORDS: special education; physical handicap; disability seriousness.

\footnotetext{
${ }^{1}$ Doutora em Educação, Professora do Curso de Terapia Ocupacional e do Programa de Pós-Graduação em Educação, UNESP, campus de Marília. ivanmelo@flash.tv.br .

${ }^{2}$ Livre-docente em Educação Especial, Professor Titular do Departamento de Educação Especial e Professor Orientador do Programa de Pós-Graduação em Educação, UNESP, campus de Marília. somote@uol.com.br .
} 


\section{INTRODUÇÃo}

Um parâmetro importante e gerenciador da elegibilidade educacional perante quadros de deficiência tem sido o da gravidade do déficit nas suas formas física, mental, auditiva ou visual. Argumenta-se sobre a necessidade de um ambiente altamente diferenciado, que disponibilize, por exemplo, equipamentos especificamente adaptados às necessidades da pessoa com prejuízos intelectuais, sensoriais ou motores em grau severo. Essa indicação seria inquestionável do ponto de vista clínico-funcional, se não houvesse a possibilidade de o usuário de um serviço especializado e diferenciado ser segregado.

Ademais, é preciso considerar que a quantificação de gravidade de uma deficiência auditiva, visual, intelectual ou da motricidade não se reduz à avaliação de capacidades funcionais específicas. Atenção também deve ser dada à demanda ambiental, pois a expressão de competências individuais emerge da interação da pessoa com o meio. Significa que as incompetências individualmente manifestadas e socialmente reconhecidas são também determinadas pelas exigências do meio.

No diagnóstico de disfunções ocupacionais, a competência é avaliada considerando-se as áreas, os componentes e os contextos de execução, sendo essa prática comum entre os profissionais terapeutas ocupacionais. Em Terapia Ocupacional e na terminologia do modelo de desempenho ocupacional (LÓPEZ et al, 2001), as áreas de execução compreendem amplas categorias de atividade humana que fazem parte da vida cotidiana, tais como as atividades de vida diária (higiene, alimentação, socialização, comunicação, etc.), as atividades produtivas (trabalho, estudo, etc.) e as atividades de lazer. Os componentes de execução (tais como os sensoriomotores, neuromusculares, motores, cognitivos, psicológicos e psicossociais) são as habilidades humanas fundamentais que, em uma variedade de graus e em diferentes combinações, são necessárias para desenvolver de forma satisfatória as atividades que compõem as áreas de execução. Os contextos de execução incluem aspectos temporais (tais como idade cronológica, idade de desenvolvimento e ciclo vital), condições de saúde e aspectos ambientes (tais como o físico, social e cultural).

Diante dessas considerações, pode-se entender que os atributos da pessoa não são os únicos fatores a influir sobre a gravidade de suas disfunções ocupacionais, e que o grau de prejuízo funcional de uma deficiência varia dependendo da atividade de vida que se constitui em parâmetro da avaliação. Por exemplo, uma mesma condição de acometimento da coluna vertebral pode caracterizar um grau suficientemente severo de deficiência para a concessão de aposentadoria, mas não necessariamente justificar a exclusão escolar, porquanto o limiar de exigência de autonomia e produtividade do sujeito no plano profissional não se aplica ao plano educacional, principalmente nas séries iniciais do ensino fundamental. Com isso, percebe-se que a gravidade de uma deficiência tem diferentes leituras, requerendo uma compreensão ampla e nas mesmas direções do conceito de deficiência. 
A maneira como a sociedade organiza e controla os recursos de acesso para a experiência das pessoas com deficiência nos diferentes segmentos da vida coletiva socialmente organizada é reveladora de práticas sociais contraditórias. As leituras sobre deficiência realizadas pela sociedade ora atendem ao princípio da cidadania, a exemplo da redução de impostos na aquisição de carros com transmissão automática para pessoas com deficiência física, determinada por lei e consensualmente aceita, ora cursam na contramão da inclusão, a exemplo da persistente polêmica quanto aos benefícios da educação inclusiva para todos os estudantes. Essas diferenças quanto ao uso e disponibilidade de recursos, para que a parcela da população com deficiência possa ter acesso à vida social comum, denunciam o uso diverso e antagônico dos tratamentos sociais para quem é diferente do padrão de normalidade.

Do ponto de vista ergonômico, o benefício da aquisição de carros adaptados, concedido somente para pessoas deficientes, poderia ser questionado. Demandando menos esforço e coordenação para a realização da atividade, o veículo de transmissão automática seria, no mínimo, recomendável aos motoristas idosos, e a estes deveria também corresponder o mesmo benefício. Se, nessa área de atividade, concede-se privilégio aos deficientes, já no ambiente escolar, ao contrário, dá-se privilégio aos normais, justificando-se a não inserção de alunos deficientes em ambiente de ensino comum sob o argumento de que a demanda dos alunos portadores de deficiências mais graves diminuiria a atenção do professor aos alunos normais. Em outras palavras, esse posicionamento parece sustentar-se na possibilidade de a presença do deficiente em classe comum ameaçar a aprendizagem e a produtividade da população estudantil normal.

A inserção incondicional de alunos deficientes em classes de ensino comum ou a sua manutenção em alguma modalidade de ensino total ou parcialmente segregado parece depender mais de posições ideológicas que de argumentos cientificamente defensáveis. Na defesa da provisão de educação de qualidade para todas as crianças e jovens em idade escolar, independentemente de suas características pessoais e condições psicossociais, socioeconômicas e etnoculturais, avistam-se essas duas possibilidades, para cuja demonstração da procedência são necessárias evidências empíricas produzidas por meio de pesquisas bem delineadas e conduzidas: (1) a possibilidade de o ensino de deficientes ocorrer exclusivamente em classe comum com a prescrição de adaptações adequadas às suas necessidades especiais juntamente com o apoio de profissionais especializados; e (2) a possibilidade de o ensino ocorrer em ambientes de ensino segregados com serviços e demandas compatíveis às necessidades especiais dos seus usuários.

A posição de inclusão radical considera vazio o argumento de que a presença de alunos deficientes em classes de ensino comum possa prejudicar a aprendizagem deles próprios e dos demais alunos. Em sua defesa, cabe a argumentação de que a promoção da experiência social nos espaços comuns da vida coletiva, na perspectiva inclusiva, requer mudanças nos cenários sociais do ponto de vista ergonômico e na forma de arranjos e manejos institucionais. Portanto, 
o sensato é que se busquem alternativas e estratégias de ação para o enfrentamento de problemas decorrentes daquele convívio do qual deve resultar a aprendizagem de todos os alunos. Esse convívio deve ser enriquecedor para todos que dele participam, sendo, para tanto, necessárias adaptações curriculares de conformidade com as necessidades de cada um. Afastar a possibilidade da experiência escolar de alunos deficientes nos espaços de ensino ocupados por alunos não deficientes é deixar tudo como está, é resistir a mudanças desejáveis e necessárias, é dificultar o avanço qualitativo na evolução social. A inclusão enseja, portanto, essa oportunidade ímpar de avanço qualitativo no modo de vida coletiva em diferentes ambientes essenciais da nossa vida.

Diante da natureza complexa das reações sociais às deficiências e dos paradoxos éticos que se apresentam quanto aos propósitos do tratamento diferenciado do deficiente, pode-se então inferir que o meio, nas suas diferentes maneiras de organização da vida coletiva, orienta a direção da adaptação do indivíduo, funcionando à semelhança da teoria de Lamarck, "[...] já que o lamarckismo é fundamentalmente uma teoria de variação dirigida" (GOULD, 1990, p.68). Nesse sentido, a justificação da experiência escolar em classe especial, ou qualquer outra modalidade segregada, pela necessidade de um ambiente altamente diferenciado para o aluno que apresenta deficiência em grau severo merece destaque e deve ser interrogada exatamente porque essa proposição configura seleção dirigida e não provoca mudanças no meio. Além disso, se a adaptação resulta da interação do indivíduo com o meio e de influências mútuas entre eles, a construção de um mundo social à parte para os diferentes não é desejável nem mesmo sob o ponto de vista biológico, pois isso reduziria as possibilidades de variação da espécie, visto que essa separação com tom de isolamento social configura a tendência de construção de ecossistemas fechados para indivíduos específicos.

Há, por outro lado, argumentos a favor do atendimento diferenciado de deficientes em serviços especializados e segregados, em função da natureza e/ ou do grau de acometimento (este evidentemente avaliado a partir de evidências objetivas e não meramente inferido em um processo de julgamento baseado em alguma característica visível ou no contexto de atendimento), o que permitiria prover serviços de qualidade melhor a seus usuários. E algumas situações, expostas a seguir, dão teor a essa posição ideológica.

A presença de alunos com deficiência física ou deficiência visual, em aulas de Educação Física, proporciona a todos uma oportunidade ímpar de vivenciar as adaptações em algumas atividades, em função da realidade da limitação deles. Não se deve admitir, entretanto, que as atividades físicas e motoras proporcionadas ao conjunto de alunos de uma classe ou escola inclusiva se restrinjam apenas àquelas das quais esses deficientes podem participar regularmente. Portanto, em algum momento, a idéia de co-participação plena pode não ser viável, o que não significa, evidentemente, que alunos deficientes devam ter aulas de Educação Física separadamente. 
O atendimento em separado pode ser necessário também em função da alta especialização requerida para prover serviço de qualidade a usuários com necessidades especiais. Por exemplo, o tratamento odontológico para portadores de hemofilia, HIV, grave descontrole neuromuscular ou distúrbio comportamental pode requerer atendimento em separado, em decorrência da necessidade de condições infraerstruturais e de recursos humanos e técnicos especiais, que não estão presentes nos serviços congêneres destinados a pessoas comuns nem podem estar presentes, dado o elevado custo da sua construção e manutenção, ao mesmo tempo em que há quantidade reduzida de usuários.

A existência de atendimento em separado, parcial ou totalmente, não configura necessariamente construção de um mundo à parte para os seus usuários. Mais ainda, graças ao atendimento de uma necessidade específica e especial, proporcionado pela existência de serviço especializado e segregado, os seus usuários podem fazer-se presentes em diferentes cenários da vida coletiva, contribuindo para a existência efetiva da variação. O que deve ser questionado é o tratamento diferenciado de deficientes, baseado na categoria à qual pertencem e nos estereótipos a ela associados. A prescrição de qualquer serviço especial deve ocorrer em função de necessidades específicas de cada indivíduo, mediante a correta avaliação das possibilidades de utilização de serviços comuns ou especiais. É a prescrição categorial, tão freqüente e naturalmente praticada até um passado recente, que deve ser evitada.

Nessa perspectiva, a idéia da evolução social deve ser analisada olhando para a totalidade dos espaços da vida coletiva. A existência de serviços especiais e segregados - significa, nessa ótica ampliada, mudanças no meio ocorridas graças à inclusão praticada radical e rigorosamente. Na medida em que há certas diferenças que impõem necessidades especiais bastante diferenciadas das de pessoas comuns, devem ser criados serviços especiais, tantos forem necessários, para que todas as pessoas deficientes, independentemente da natureza e do grau de acometimento, possam ter a oportunidade de receber serviços de qualidade. Não seria, nessa perspectiva, aceitável a possibilidade de algum deficiente não receber serviço de qualidade por considerar-se imprescindível o seu atendimento junto com outros usuários, em espaço comum, em nome da inclusão. Deve ficar claro para todas as pessoas envolvidas que são esses serviços especiais que muitas vezes são segregados e não os seus usuários. A segregação dos usuários de algum serviço especial não é resultado de alguma característica intrínseca a este. É resultado do modo como ele é utilizado. A segregação dos usuários é construída socialmente e portanto o seu desfazimento é também social.

É a totalidade do ambiente da vida coletiva que se modifica, buscando ajustar-se à ampla diversidade, de tal maneira que do processo evolucionário da espécie humana não sejam excluídos aqueles que apresentam necessidades muito diferenciadas da maioria dos seus pares. É a ampla diversidade e heterogeneidade na totalidade do ambiente coletivo que parece assegurar de fato a participação efetiva de todos os cidadãos, com as mais variadas diferenças, nas atividades que 
conduzem à evolução social do homem. É essa ampla variação ambiental que otimiza as condições evolucionárias capazes de dar as melhores (não necessariamente iguais) oportunidades àqueles que, se mantidos no atendimento comum destinado a todos os usuários sob a expectativa da igualdade, seriam excluídos da participação nessa história. É a inclusão praticada radical e rigorosamente.

Qualquer que seja a opção assumida para a construção de uma sociedade inclusiva, a gravidade do acometimento envolve questões que precisam ser investigadas profundamente. Como observa Omote (1995; 1996), o que torna o indivíduo deficiente aos olhos sociais certamente não é apenas o déficit que ele apresenta, mas o significado dessa condição desviante. A diminuição na capacidade auditiva pode ser interpretada como altamente incapacitante por músicos. Já no mundo dos sommeliers, uma pequena alteração na capacidade gustativa pode ser uma grande tragédia; assim o é o prejuízo mínimo na capacidade olfativa para os perfumistas. Portanto, a gravidade do acometimento não é um fenômeno estritamente clínico; talvez seja uma dimensão da realidade social de um fenômeno clínico.

$\mathrm{Na}$ construção dessa realidade social, concorrem as características do ambiente no qual se realiza a experiência escolar do aluno identificado como deficiente, conforme demonstrou o estudo realizado por Araújo (1998). O reconhecimento da deficiência de um aluno pode depender do ambiente no qual se realiza a experiência escolar, mais do que das características dele próprio. A gravidade do acometimento percebida pode, assim, ser legitimada pelo tratamento diferenciado recebido por esse aluno.

Saliente-se que as adaptações, indicadas em função da incapacidade motora e às quais se atribui uso exclusivo em atendimentos especializados, tendem a exacerbar a percepção da gravidade do déficit. Diante disso, a recomendação de ensino especializado ao deficiente, mesmo quando justificado por fatores clínicos e funcionais, deve suscitar questionamentos sobre os efeitos colaterais, sobretudo de natureza psicossocial, dos recursos utilizados no tratamento. A prescrição de qualquer terapêutica requer atenção e controle por parte do profissional sobre os eventuais efeitos indesejáveis dos procedimentos aplicados. Isto não significa, evidentemente, que se não deve prescrever tais procedimentos. Seus efeitos colaterais indesejáveis é que precisam ser controlados, reduzindo-os o máximo possível. Em se tratando de procedimentos educacionais especiais, tal controle deve ser exercido no plano das relações interpessoais e sociais construídas no contexto escolar.

O que é preciso, antes de tudo, é um melhor conhecimento da diversidade das capacidades humanas e de seus requisitos ambientais, para que mudanças introduzidas pela seleção dirigida aumentem a harmonia entre o organismo e o meio em termos qualitativo com abrangência populacional.

Considerando que o uso de recursos adaptados e de modalidades segregadas de atendimento especial pode representar não apenas alternativas de 
tratamento diferenciado do deficiente, mas também a própria deficiência, no seu sentido social desvantajoso, o presente estudo parte da hipótese de que a gravidade de uma deficiência, tal como percebida, inclui significados de diferença, desvio e estigma. Assim, o seu objetivo é investigar a proporção em que a percepção da gravidade de um acometimento depende da natureza do ambiente escolar em que ocorre a educação do aluno deficiente e da extensão desse acometimento. Investiga também a relação entre a formação profissional das pessoas e a percepção delas acerca da gravidade de uma deficiência.

\section{Método}

\subsection{PARTICIPANTES}

Participaram deste estudo 97 estudantes de um curso de Pedagogia, sendo 38 alunos do $3^{\circ}$ ano, 30 alunos do $4^{\circ}$ ano que estavam freqüentando a Habilitação em Educação Infantil e 29 alunos do $4^{\circ}$ ano que freqüentavam a Habilitação em Educação Especial. A opção por essas duas séries do curso de Pedagogia se deveu ao fato de caracterizarem duas fases importantes na formação do educador: a fase final da formação comum e a fase dirigida à formação do especialista em Educação Infantil e Educação Especial.

\subsection{MATerial}

Foi utilizado um questionário apresentado em quatro formas distintas de descrição da realização de determinada atividade escolar, tendo como elementos centrais da apresentação do cenário: o recurso de acesso ao currículo, a capacidade funcional do agente da ação e o contexto ou local da experiência escolar.

O acometimento funcional do agente da ação foi descrito com base na sua necessidade do uso de adaptação do teclado de computador (recurso de acesso ao currículo) para o exercício da leitura e escrita em vista da dificuldade de preensão do lápis. Compuseram o cenário descritivo da capacidade funcional duas descrições de déficit motor do usuário do recurso de acesso ao currículo, caracterizando o acometimento motor parcial e o global. A descrição de que o recurso era indicado pela dificuldade de uso do lápis sob condições normais de preensão, devido ao déficit de função motora dos membros superiores, caracterizou a informação de acometimento motor parcial. A informação de que o recurso era indicado na presença de dificuldade motora para uso do lápis, acrescida da indicação de dificuldade para manutenção do equilíbrio na posição sentada e de dificuldade de deambulação independente, caracterizou a informação de acometimento motor global.

Na indicação da experiência escolar, foram destacados dois ambientes de ensino onde acontecia a atividade, quais sejam, a classe comum e a classe especial.

As duas modalidades de ensino e as duas condições funcionais, devidamente combinadas, foram organizadas em quatro tipos de condições: a) 
uso do recurso em classe comum e acometimento parcial (CCAP), b) uso do recurso em classe comum e acometimento global (CCAG), c) uso do recurso em classe especial e acometimento parcial (CEAP) e d) uso do recurso em classe especial e acometimento global (CEAG).

\subsection{Procedimento}

Os dados foram coletados em salas de aula freqüentadas pelos participantes, em uma única sessão de aplicação do questionário, durante o intervalo de aulas. Eram duas classes do $3^{\circ}$ ano, uma classe da Habilitação em Educação Infantil e uma classe de Educação Especial. Em cada classe, os questionários relativos às quatro versões de condições (CCAP, CCAG, CEAP e CEAG) foram distribuídos alternadamente, de maneira a reduzir a possibilidade de ocorrência de resposta compartilhada entre os vizinhos e assegurar uma distribuição relativamente eqüitativa dessas quatro condições. A coleta de dados nas quatro classes foi concluída no decorrer de duas semanas.

Como os participantes pertenciam a três turmas com perfis um pouco diferenciados de formação do educador e as quatro combinações de acometimento e modalidade escolar freqüentada foram apresentadas mais ou menos eqüitativamente em cada turma, preliminarmente será feita a análise intragrupo, comparando a distribuição de freqüência de atribuição de grau leve ou severo de acometimento a cada uma das condições específicas. Será, em seguida, realizada análise global, comparando as freqüências de atribuição de grau leve ou severo de acometimento de todos os participantes.

\section{Resultados E Discussão}

Os resultados gerais de distribuição de freqüências de atribuição de grau leve ou severo ao acometimento podem ser vistos na tabela 1 . Um rápido exame mostra que pode ser observada uma tendência crescente na freqüência de atribuição de grau severo ao acometimento motor em função da extensão do mesmo e sobretudo, da modalidade de ensino.

Tabela 1- Freqüência de atribuição de grau leve ou severo pelos grupos para cada uma das condições.

\begin{tabular}{|c|c|c|c|c|c|c|c|c|c|}
\hline \multirow{2}{*}{$\begin{array}{l}\text { Informação } \\
\text { Grupos }\end{array}$} & \multicolumn{2}{|c|}{ CCAP } & \multicolumn{2}{|c|}{ CCAG } & \multicolumn{2}{|c|}{ CEAP } & \multicolumn{2}{|c|}{ CEAG } & \multirow{2}{*}{ Total } \\
\hline & Leve & Severo & Leve & Severo & Leve & Severo & Leve & Severo & \\
\hline $3^{\circ}$ ano de Pedagogia & 3 & 6 & 4 & 5 & 2 & 6 & 2 & 10 & 38 \\
\hline $\begin{array}{l}\text { Habilitação } \\
\text { em Educação Infantil }\end{array}$ & 4 & 3 & 3 & 5 & 3 & 5 & 1 & 6 & 30 \\
\hline $\begin{array}{l}\text { Habilitação em } \\
\text { Educação Especial }\end{array}$ & 3 & 3 & 2 & 5 & 2 & 6 & 2 & 6 & 29 \\
\hline Total & 10 & 12 & 9 & 15 & 7 & 17 & 5 & 22 & 97 \\
\hline
\end{tabular}


A prova exata de Fisher evidenciou que as freqüências de atribuição do grau leve ou severo ao acometimento motor, nas condições CCAP e CCAG, não diferem significantemente em nenhum dos três grupos de estudantes ( $p>0,05)$. Semelhante análise foi feita, comparando as freqüências de atribuição de grau leve ou severo, nas condições CEAP e CEAG, encontrando-se resultados que indicam não haver diferença estatisticamente significante devida à extensão do acometimento também no contexto de escolarização em classe especial ( $p>0,05)$.

A tabela 1 mostra que, na condição de escolarização em classe especial, comparativamente à condição de escolarização em classe comum, há freqüência maior de atribuição de grau severo do que o leve, tanto para acometimento parcial quanto para o global. Assim, procedeu-se à comparação das atribuições nas condições CCAP e CEAP, e das atribuições nas condições CCAG e CEAG, por meio da prova exata de Fisher. Os resultados indicam que tanto na condição de acometimento parcial quanto na global, não há diferença estatisticamente significante ( $p>0,05)$, entre a condição de escolarização em classe comum e em classe especial, nas freqüências de atribuição de grau leve ou severo, em nenhum dos três grupos de estudantes.

Como as freqüências observadas são muito baixas, decidiu-se reunir os dados dos três grupos de estudantes para proceder à análise global dos efeitos do contexto de escolarização e da extensão do acometimento sobre a atribuição de grau leve ou severo. Preliminarmente, foi feita a comparação entre os três grupos de estudantes, encontrando-se resultado que indica praticamente a igualdade nas respostas $\left(\chi^{2}=0,476 ; \mathrm{p}>0,05\right)$.

Com os dados dos três grupos reunidos, as freqüências de atribuição do grau leve ou severo foram comparadas por meio do qui-quadrado. Na condição CCAP, o grau leve foi atribuído por 10 participantes e o severo por 12 participantes; na condição CCAG, as freqüências de atribuição foram 9 e 15, respectivamente. Procedendo aos competentes cálculos, o valor do $\chi^{2}$ encontrado foi de 0,061 , virtualmente nulo. Portanto, pode-se apontar que, no contexto de escolarização em classe comum, a informação de acometimento parcial ou global não tem efeito estatisticamente significante sobre a atribuição de grau leve ou severo. Na condição CEAP, o grau leve foi atribuído por 7 participantes e o grau severo por 17; na condição CEAG, as freqüências de atribuição foram 5 e 22, respectivamente. $\mathrm{O} \chi^{2}$ apurado, no valor de 0,318 , indica que não há diferença estatisticamente significante na atribuição de grau leve ou severo devida à informação sobre o acometimento parcial ou global, também no contexto de escolarização em classe especial.

As análises realizadas até aqui permitem concluir que nem o contexto de escolarização (classe comum ou classe especial) nem a extensão do acometimento (parcial ou global) exerceram efeitos estatisticamente significantes sobre a atribuição de grau leve ou severo ao acometimento.

Apesar de os resultados não indicarem efeitos significantes, os dados sinalizam tendências que foram compartilhadas sistematicamente pelos 
participantes dos três grupos nas quatro condições apresentadas. A tendência verificada foi a de se atribuir grau severo mais freqüentemente ao acometimento global do que ao acometimento parcial, nos dois contextos de escolarização; semelhantemente, observou-se atribuição de grau severo mais freqüentemente ao aluno em contexto de classe especial do que no de classe comum, nas duas condições de extensão do acometimento.

A condição que indicava o uso do recurso adaptado em classe comum e acometimento parcial (CCAP) obteve 54,5\% de atribuição de grau severo e 45,5\% de grau leve, do total de 22 respostas. A condição que indicava o uso do recurso adaptado em classe comum e acometimento global (CCAG) obteve 62,5\% de atribuição de grau severo e $37,5 \%$ de grau leve, do total de 24 respostas. A condição que indicava o uso do recurso em classe especial e acometimento parcial (CEAP) obteve 70,8\% de atribuição de grau severo e 29,2\% de grau leve, do total de 24 respostas. A condição que indicava o uso do recurso em classe especial e acometimento global (CEAG) obteve 81,5\% de atribuição de grau severo e 18,5\% de grau leve, do total de 27 respostas. Tudo isto pode ser visualizado claramente no Gráfico 1.

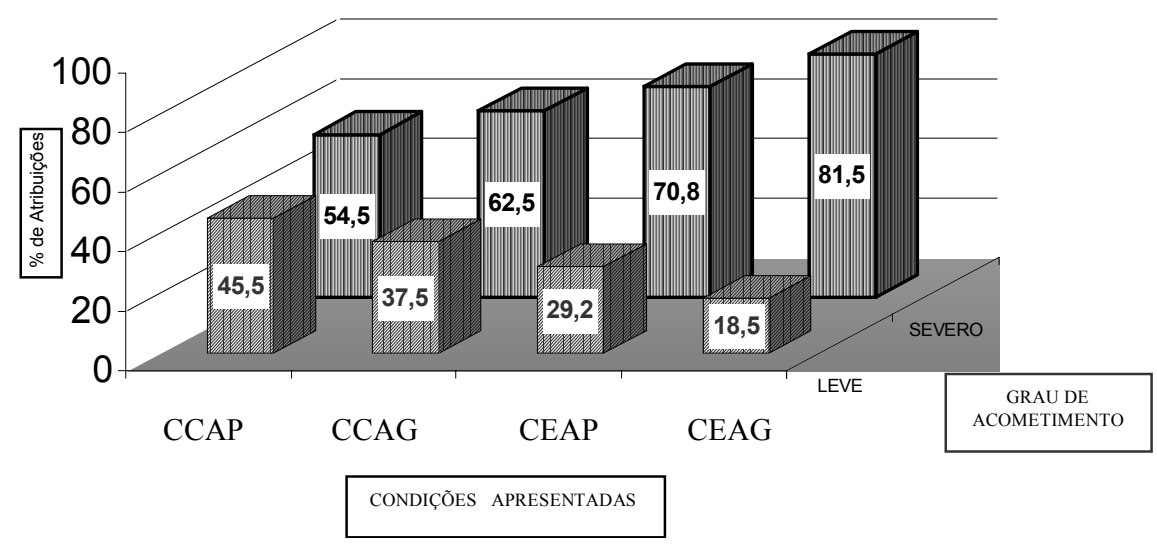

Gráfico 1- Atribuição de grau leve ou severo ao acometimento motor segundo a natureza da experiência escolar e extensão acometimento motor.

A freqüência de atribuição de grau severo ao acometimento motor parcial em situação de ensino especial foi superior à freqüência de atribuição de grau severo ao acometimento motor global em situação de ensino comum. Esses resultados mostram que a informação sobre o contexto de escolarização influiu mais acentuadamente para a atribuição de grau severo ao acometimento do que a informação sobre a extensão do acometimento. A informação sobre a experiência escolar em ambiente de ensino segregado tendeu a exacerbar a idéia de severidade do acometimento motor, confirmando os efeitos negativos do ensino em ambiente 
segregado, na perspectiva de atribuição de gravidade à deficiência. A atribuição de maior gravidade ao aluno cuja escolarização ocorre em contexto de ensino segregado pode esconder fenômenos de natureza psicossocial, que devem ser investigados para uma adequada compreensão das deficiências e das reações sociais frente a elas, institucionalizadas na forma de tratamentos especializados, que muitas vezes adquirem caráter segregativo. A colocação em um serviço especializado parece legitimar a condição de alguém como deficiente, sem levar em conta as inúmeras possibilidades de vieses nesse encaminhamento e tratamento, como as pesquisas amplamente já demonstraram (ABRAMOWICZ, 1995; ALMEIDA, 1984; DENARI, 1984; MACHADO, 1994; PASCHOALICK, 1981; PIRAVANO, 1996; RODRIGUES, 1982; SCHNEIDER, 1974).

Deve-se apontar que não é a colocação per se em serviço especializado que leva o usuário a ser segregado socialmente, como foi apontado por Omote (1995, 1999, 2000) em várias ocasiões. O caráter segregativo não é propriedade inerente a nenhum serviço especializado. A classe especial para deficientes mentais, em particular, foi amplamente utilizada para promover a exclusão de alunos com determinadas características, não necessariamente associadas à deficiência mental. As relações sociais construídas no interior das escolas públicas, envolvendo alunos de classes especiais, freqüentemente serviam para a incapacitação social deles e a legitimação da condição cuja presumida posse havia levado a esse tratamento diferenciado.

\section{Conclusão}

Os resultados revelam a tendência de as informações sobre a modalidade escolar freqüentada e sobre a extensão do acometimento influírem na atribuição do grau de severidade desse acometimento. Os efeitos da informação sobre o contexto escolar parecem ser ligeiramente maiores que os da informação sobre a extensão de comprometimento.

Seria esperado que os participantes que cursaram disciplinas optativas em Educação Especial e sobretudo os da Habilitação em Educação Especial fizessem suas atribuições de grau leve ou severo com base na extensão do acometimento e não com base na modalidade de escolarização, uma vez que a sua formação contempla aspectos educacionais e clínicos das deficiências.

A atribuição de gravidade às deficiências deve apoiar-se na relação do indivíduo com o meio e na sua capacidade de realizar tarefas. Contudo, observase que, no presente estudo, é o tratamento educacional institucionalizado que parece influir no julgamento da intensidade da gravidade do déficit da capacidade motora. Nesse sentido, a percepção de severidade de acometimentos motores não deve constituir-se em um referencial de elegibilidade educacional a ambiente de ensino especializado, uma vez que esta prescrição parece "legitimar" o julgamento. Tudo isto recomenda, na realidade, a realização de avaliações rigorosas, além de reavaliações periódicas, tratando as conclusões dessas avaliações como uma 
hipótese de trabalho e não como uma descrição fidedigna e inteiramente confiável da capacidade ou incapacidade absoluta do aluno. Essa postura é essencial, considerando que todo e qualquer julgamento está sujeito a vieses de diferentes naturezas, ainda que existam claros indicadores, como no caso dessas avaliações.

Os resultados encontrados também sugerem que tratamentos diferenciados em ambientes representativos da população deficiente configuram anormalidade, talvez porque a concepção de deficiência implique a hierarquização da diferença, e a classe especial se apresenta como uma forma pragmática de confirmação da crença nas diferenças hierarquizadas. Investir na continuidade da exploração desta hipótese pode ser crucial, para que se situe melhor a questão da gravidade de quadros de deficiência, do ponto de vista conceitual e também no âmbito das ações sociais convencionalmente organizadas e especificamente dirigidas à população que apresenta deficiência nas diferentes instituições sociais.

Demonstrando que a descrição da capacidade funcional não influiu significantemente nas respostas dos participantes e que os estudantes da Habilitação em Educação Especial não se diferenciaram dos demais estudantes do curso de Pedagogia, este estudo revela que conhecimentos específicos englobando os aspectos clínicos e sociais da deficiência não são suficientes para orientar a percepção de sua gravidade. Diante dos resultados obtidos neste estudo, há que se considerar que a justificação de tratamento diferenciado em ambiente segregado pelo argumento da gravidade de déficits funcionais merece e deve ser questionada, na medida em que nem sempre o encaminhamento a serviço especial resulta de medidas qualitativas e quantitativas confiáveis do déficit funcional, obtidas por meio de procedimentos e instrumentos de avaliação confiáveis. Con si derand o que as condutas especializadas no campo educacional e da reabilitação têm como princípio básico a atenuação da gravidade do acometimento, quaisquer encaminhamentos e procedimentos que possam exacerbá-la devem ser tratados com critério, avaliando-se rigorosamente o balanço entre os ganhos e os efeitos indesejáveis não pretendidos. Nessa direção, e dada a importância dos resultados obtidos neste estudo, recomenda-se a continuidade da investigação mediante a ampliação do número de participantes e de outros arranjos que possam aumentar a sensibilidade do experimento, a fim de se verificar a realidade das tendências observadas.

Em suma, este estudo remete à busca de esclarecimentos sobre as bases conceituais da idéia de gravidade que norteiam a avaliação e elegibilidade educacional do deficiente, alertando para a possibilidade de que a deficiência, representando uma condição socialmente desvantajosa, seja percebida e tratada como grave, independentemente da extensão em que o indivíduo se afasta dos limites de normalidade de desempenho funcional. $\mathrm{O}$ desvio per se pode ser interpretado como algo desvantajoso, como amplamente demonstraram os experimentos de Freedman e Doob (1968). Se esse desvio tem a significação de uma deficiência, então ser membro da respectiva categoria pode ser visto como algo muito grave. 


\section{REFERÊNCIAS}

ABRAMOWICZ, A. A Menina Repetente. Campinas: Papirus, 1995.

ALMEIDA, C. S. Análise dos Motivos de Encaminhamento de Alunos de Classes Comuns a Classes Especiais de Escolas Públicas de Primeiro Grau. 1984. Dissertação (Mestrado em Educação Especial) - Universidade Federal de São Carlos, São Carlos.

ARAÚJO, R.C.T. Significado de recursos adaptados utilizados na educação de deficientes físicos. Marília, 1998. 90p. Tese (Doutorado Educação)- Faculdade de Filosofia e Ciências, UNESP, Marília.

DENARI, F. E. Análise de Critérios e Procedimentos para a Composição Clientela de Classes Especiais para Deficientes Mentais Educáveis. 1984. Dissertação (Mestrado em Educação Especial) - Universidade Federal de São Carlos, São Carlos.

FREEDMAN, J. L.; DOOB, A. N. Deviancy: The Psychology of being different. New York: Academic Press, 1968.

GOULD, S.J. O polegar do Panda: Reflexões sobre história natural. São Paulo: Martins Fontes, 1990

LÓPEZ, B.P. IN: LÓPEZ, B.P.; MOLINA, P.D.; ARNAIZ, B.N. Conceptos fundamentales de terapia ocupacional. Argentina:Panamericana, 2001.

MACHADO, A. M. Criança de Classe Especial. São Paulo: Casa do Psicólogo, 1994.

OMOTE, S. A integração do deficiente: um pseudoproblema científico. Temas em Psicologia, n.2, p.55-62, 1995.

. Perspectivas para conceituação de deficiência. Rev. Brasileira de Educação Especial, v.2, n.4, p.127-135, 1996.

Normalização, integração, inclusão... Ponto de Vista (Revista do Curso de Pedagogia da UFSC), v. 1, n. 1, p. 4 -13, 1999.

Classes especiais: comentários à margem do texto de Torezan \& Caiado. Revista Brasileira de Educação Especial, v. 6, n. 1, p. 43-64, 2000.

PASCHOALICK, W. C. Análise do Processo de Encaminhamento de Crianças às Classes Especiais para Deficientes Mentais Desenvolvido nas Escolas de $1^{\circ} \mathrm{Grau}$ da Delegacia de Ensino de Marília. 1981. Dissertação (Mestrado em Educação) Pontifícia Universidade Católica de São Paulo, São Paulo.

PIRAVANO, K. R. C. Caminho Suado - a Trajetória Escolar de Alunos Encaminhados para Classes Especiais de Educação Especial para Deficientes Mentais em Escolas Públicas da Rede Estadual de São Paulo. 1996. Dissertação (Mestrado em Educação) - Universidade Estadual Paulista, Marília. 
ARAÚJO, R.C.T.; OMOTE, S.

RODRIGUES, O. M. P. R. Caracterização das Condições de Implantação e Funcionamento de Classes Especiais e Caracterização das Condições de Avaliação de Classes Regulares de $1^{\text {a }}$ Série de $1^{\circ}$ Grau, para Fundamentar uma Proposta de Intervenção. 1982. Dissertação (Mestrado em Educação Especial) - Universidade Federal de São Carlos, São Carlos.

SCHNEIDER, D. "Alunos Excepcionais": um Estudo de Caso de Desvio. Em G. Velho (Org.) Desvio e Divergência: uma crítica da patologia social. Rio de Janeiro: Zahar, 1974, p. 52-81. 